\title{
Discourse Analysis and Development of English Listening for Non-English Majors in China
}

\author{
Yinxiu $\mathrm{Ji}^{1}$ \\ ${ }^{1}$ School of Foreign Languages, China West Normal University, China \\ Correspondence: Yinxiu Ji, School of Foreign Languages, China West Normal University, No. 1 ShiDa Road, \\ 637009 Nanchong, Sichuan, China. Tel: 86-136-9624-5567. E-mail: jyxiu@163.com
}

Received: November 11, 2014 Accepted: December 15, 2014 Online Published: January 20, 2015

doi:10.5539/elt.v8n2p134 URL: http://dx.doi.org/10.5539/elt.v8n2p134

\begin{abstract}
Traditional approach of listening teaching mainly focuses on the sentence level and regards the listening process in a passive and static way. To compensate for this deficiency, a new listening approach, that is, discourse-oriented approach has been introduced into the listening classroom.

Although discourse analysis is a comparatively new field and there are still considerable gaps in our knowledge about it, it has in effect provided new insights into language teaching involving listening. Some theories in discourse analysis such as cohesion, coherence, schema, relevance, etc. are critically important in enhancing the students' listening comprehension ability and improving their communicative competence.

The present study was undertaken to observe the correlation between the theories of discourse analysis and the nature of listening comprehension and to further trace the developmental differences in the learners' listening proficiency brought from this discourse-oriented approach. Through analysis of listening difficulties and experiment, the present study confirmed the effectiveness of discourse-oriented approach, which might add a bit more to the understanding of discourse analysis. Pedagogically, it suggested a relatively uncomplicated procedure that might have considerable and varied payoffs in terms of listening teaching and learning.
\end{abstract}

Keywords: discourse analysis, listening comprehension, schema, cohesion and coherence, relevance

\section{Introduction}

Based on structural linguistics and behaviorism, traditional approach of listening teaching only focuses on the form and structure of language, and views listening process in a static and passive way. Students function as a tape recorder by absorbing and storing aural messages in much the same way as the machine. The listening teaching only stays at sentence level and the discourse meaning is greatly ignored. In fact, when people listen, whether they are listening to a lecture, a news broadcast, a joke, or are engaging in a conversation, they are listening to discourse.

With the development of functional linguistics in the 1970s, people turned to the study of the social functions of language. Language is considered as a way of communication, a means of thought but not an isolated structural system. At the same time, with the development of cognitive psychology, many researchers began to pay attention to the study of listening comprehension process and try to reveal the nature of listening comprehension with the aid of discourse analysis theories such as the discourse macro-structure, cognitive schema, context, relevance, cohesion and coherence. They found that although the discourse is organized by a series of sentences, the understanding of a sentence does not necessarily mean the understanding of a text. The listening comprehension of a discourse involves many factors. In order to compensate for the deficiency of traditional listening comprehension approach, a new one, that is, discourse-oriented approach, was introduced into the classroom.

Although the research achievements of discourse analysis have been largely applied to EFL reading and writing teaching, the traditional method still shrouds the field of listening to a certain extent. Therefore, this research is intended to first identify the reasons for senior English majors' listening failure by a semi-open interview, then apply some relevant discourse analysis theories to the listening teaching in purpose of finding out some effective pedagogical implications available for college English listening teaching and making it clear that discourse-oriented approach can be and should be used in listening teaching and learning. It answers the call 
from the following aspects:

1) In language teaching, there has been a growing tendency to become more 'discourse-oriented'. Compared with sentence-oriented approach, we have become increasingly aware that discourse-oriented approach to listening teaching is more helpful to the teachers and the students.

2) Listening comprehension is definitely not a passive activity. In the listening process, participants must take full advantage of their prior knowledge related to the listening materials. Meanwhile, they must do their utmost to seek out the relevant links. The process of listening is virtually a process of presumption, inference, verification, reassumption, reverification and memorization. Schema theory and relevance theory in discourse analysis provide us with forceful instructions. So in this paper, the present author will adopt both schemata theory and relevance theory as her theoretical foundation.

3) It seems impossible to arrive at an adequate interpretation of a certain listening text. Therefore, there is no need to study text sentence by sentence. According to Harris (1952, p. 25), language does not exist in unrelated words and sentences but in cohesive and coherent discourse. Some language teaching methodologists therefore point out that discourse must be taken into account in English teaching. In this sense, discourse analysis gives us a new insight to listening comprehension teaching.

\section{Literature Review}

\subsection{Concepts of Discourse and Discourse Analysis}

\subsubsection{Discourse}

There are a variety of definitions to discourse. Gillian Brown and George Yule (1987, p. 76) define discourse as "language in use". And according to Guy Cook $(1989$, p. 45), discourse is a stretch of "language perceived to be meaningful, unified and purposive". Schiffrin (1987, p. 87) points out that functional lists and formalists view discourse differently. The former defines the study of discourse as the study of "any aspect of language use" because discourse is interdependent with social life and its analysis interacts with meanings, activities, and system outside of itself. In this paper the author will adopt the functionalist view and set forth the following statement as the working definition of discourse: Discourse refers to a meaningful series of utterances used in specific context or stretches of language perceived to be meaningful, unified and purposive. A discourse may be either a sentence or a continuous stretch of language larger than a sentence, constituting a coherent unit. It is not a grammatical unit but a semantic and even a pragmatic one.

\subsubsection{Discourse Analysis}

What is discourse analysis about? According to McCarthy (1991, p. 121), it is concerned with the study of the relation between language and the context in which it is used. It is both a study of the formal linguistic qualities of stretches of language by individuals and groups. To make it clearer, let's compare it with another area of linguistics: grammar. Here are two examples:

\section{(1) I handed Paul the canteen of water. He drank a little and handed it back to me. I drank and hung it back up.}

\section{(2) I drank and hung it back up. He drank a little and handed it back to me. I handed Paul the canteen of water.}

It's very obvious that the sentences in (1) form an acceptable English discourse but not in (2) which is not coherent. However, the discourse in (2) is really grammatical according to the rules of grammar. The contrast illustrates that we must look beneath the surface to understand discourse structure and to find how stretches of language are considered in their full texture, social and psychological context become meaningful and unified for their users. That's what discourse analysis is mainly concerned about. The rule of grammar is just a resource for the discourse to conform to them when needed and depart from them when not. What matters is not the discourse's conformity to rules, but it communicates and is recognized by its receivers as coherent.

\subsection{A Brief Historical Overview of Discourse Analysis}

As a new branch of linguistics, discourse analysis got its independence at the end of 1960s and the early1970s, which involved the linguistics, philosophy, sociology, psychology, anthropology, cognitive science etc. Over the past three decades, the study of discourse analysis has seen a considerable growth. Some theories of discourse analysis such as cohesion, coherence, relevance and so on are applied to foreign language teaching and are very important for improving the language interpretation, esp. for writing, reading and listening comprehension. For the sake of clarity and convenience in later discussion, before going on to research the discourse in English listening comprehension, the author will first make a sketchy summary of the history, concepts and major theories in the discipline of discourse analysis. 
Discourse analysis is the study of the relationship between language and its context. It is associated with different disciplines, including linguistics, semiotics, psychology, anthropology and sociology. It was American linguist Zellig Harris who was the first linguist to bring forward discourse analysis. In 1952, in his Discourse Analysis, he tried to use structural methods to analyze coherent spoken and written discourse beyond sentence and link language study with culture. In 1960s, some sociologists (e.g. Sacks, Schegloff, Jefferson, et al) raised to a new level the studies of discourse analysis. They tried to reveal the role of human beings and the influence of language use with discourse analysis in social communication and context as well as to explore the principles in communication. At the same time, German linguists made a great contribution to discourse analysis. Text linguistics was first put forward by a former West German linguist H. Winrich in 1967. He said that all of the language study should between discourse framework, otherwise there is no linguistics. In 1970s, a lot of famous scholars (e.g. T. A. Van Di ji, Leech, Grice, Brown, Levinson, Sacks, Schegloff, Jefferson) were engaged in discourse analysis research. Among them, Jefferson, Sacks and Schegloff made a great contribution to it. They realized the importance of taking turn when people are talking to each other and summarized rules and regulations of conversations. They created turn-taking theory on the basis of conversational analysis. During this period the famous book cohesion in English was published by Halliday and Hasan (1972, p. 2). They defined text as any passage, spoken or written, of whatever length, that does form a unified whole. In 1980s, the discourse analysis got full development as an independent discipline.

After decades of development, this field is now taking on a vigorous look. Handbook of Discourse Analysis by Van Dijik reported the fruitful results of discourse analysis in a systematic and comprehensive way. The relevance theory and the systematic functional grammar also contributed a lot to the development of the discourse analysis. The application of the discourse analysis to the foreign language teaching, language acquisition and language development also contributes one important part of the discourse analysis and made tremendous progress in recent years. Many books were written on it, among which, M. McCarthy's Discourse and Language Education (1992) and Language as Discourse (McCarthy \& Carter, 1994) are the most influential. In China, there are also some scholars who are specialized in the discourse analysis and represented by $\mathrm{Hu}$ Zhuanglin, Xu Jiujiu, Chen Ping, Huang Guowen, Zhang Delu et al.

With the development of discourse analysis, the Chinese foreign language teachers also shifted their attention to the fostering of discourse abilities and communicative competence which can be reflected by the demands of "Syllabus for College English" designed under the auspices of the State Education Commission. According to the syllabus, students' abilities of finding the main idea, retaining details, making influences, anticipating forthcoming materials, etc. should be improved. The appendix of the syllabus further stipulates that students should learn the way of interpreting discourse through context or co-text, identifying or organizing discourse structures by using knowledge of cohesion and coherence. Therefore, as a new discipline in applied linguistics, discourse analysis will be of great value and importance for language teaching and learning.

\subsection{The Current Teaching Situations of Listening}

The traditional listening teaching approach greatly winders the improvement of the students' listening comprehension skills at a higher level. However, it still shrouds the field of listening teaching to a certain extent in some colleges and universities nationwide, which is a real headache. If we look closely at the present situation of listening leaching in most schools, we can still easily detect some common characteristics of the traditional listening teaching. In a typical traditional listening class, teachers usually begin a listening class with introducing some difficult words as well as some brief background knowledge in relation to the upcoming listening text. They then turn on the tape-recorders, asking learners to finish the exercises, teachers check the answers and play the tape many times, sentence by sentence, without any explanation and any instruction of listening strategies or skills. The result is that listeners turn their ears up to the listening text only to be overwhelmed by streams of unfamiliar, strange sounds. Under such circumstances, listeners easily get bored and tired for lack of interest and enthusiasm. In such a teacher-dominated class, listeners are usually demotivated and reduced to passive receivers of the incoming input. What's worse, learners are very likely to get into bad and harmful listening habits. As a consequence, listeners are likely to undergo repeated experience of failure. When they come across the same problems again later, they will still be at a loss. More terribly, teachers usually tend to focus on the outcomes of listening, rather than listening itself, upon product rather than process, which can be reflected when success in listening is measured by correct responses to questions or tasks. When a learner supplies a correct answer, there is almost no indication as to how that answer has been arrived at. Such an approach to teaching listening is more like testing listening rather than teaching how to listen and how to cope with the students' listening problems in the class. As a matter of fact, wrong answers can be seen to be more significant than correct ones. The function of the teacher should be to identify and redress learners' weaknesses as listeners. 


\section{Methodology}

\subsection{Subjects}

The subjects in the present study are 60 randomly-chosen non-English majors in the foreign language department of a university in China enrolled in the year of 2012. The subjects, at the time of data collection, had been learning English as a foreign language in Chinese schools for 9 year. In the present study, the 60 subjects were divided into two classes: class A and class B. Class A was the experimental one which employed the discourse-oriented approaches and Class B was the control one which sticks to the traditional approach. Randomization was used to control the effects of the extraneous variables.

\subsection{Instruments}

Two data collection instruments are used in the present study: semi-structured interview and test. In order to find the answers to research question one, that is, what are the difficulties students are faced in listening comprehension? A semi-structured interview is conducted before the teaching experiment so as to prove whether the listening difficulties are connected with discourse or not. If the difficulties are connected with discourse, the experimental study can be continued. For the experimental study, the listening part of CET-4 (College English Test in China-Band 4) are employed to answer the research question, that is, whether the discourse analysis model can help non- English majors make further improvement in listening comprehension or not?

\subsection{Procedure}

For the interview, totally 12 subjects were chosen by the present author according to their different levels of English listening proficiency based on their final achievements in listening discourse. During the interview, the subjects were guided to describe their difficulties they have met with when they try to improve their listening proficiency. All of the participants showed great cooperation during the whole process. After the interview, the present author, with the help of other two teachers, listened to the recordings and analyzed and generalized the difficulties of those subjects.

For the experimental research, eight weeks were devoted to the teaching experiment. During this course, it was the author to teach the two classes. The subjects of each class had listening course twice a week. Both of the two classes studied in the language lab. The only difference between the two classes was the listening teaching approach. At the end of the experiment, a listening test was conducted in these two classes to examine the teaching result of the discourse-oriented approach.

\subsection{Data Collection}

The interview was conducted by the researcher herself with a tape-recorder used to record the answers of the subjects. After the interview, the present author, with the help of other two teachers, listened to the recordings and analyzed and generalized the difficulties of those subjects. The final achievements of the two classes would be input into the computer to do the independent and paired samples test with the help of the software SPSS 11.0 .

\section{Results and Discussion}

\subsection{The Difficulties Students Have in Listening Process}

\subsubsection{Confidence}

Many language learners fail to realize that when they listen to their first language they do not actually hear every word. They also fail to appreciate that we integrate linguistic knowledge with our existing experience and knowledge of such things as topic and culture, and do not need to hear every word. This means that learners often have unrealistic expectations and try to understand each word of a listening text. As Faerch and Kasper (1986, p. 265) pointed out: 'such total comprehension ...is a misconception of how normal comprehension works in the native language'. Learners' anxiety can be exacerbated by a classroom procedure which does not contextualize the text or prepare the topic by activating prior knowledge; in other words, a procedure which asks students to 'Listen to the text and then answer the questions' add students anxiety instead. This tests listening ability rather than aiming to teach it. Adults returning to English language learning whose earlier experiences have been of this nature may well have developed negative perceptions of their ability as listeners and a major task for the teacher will be to build confidence. This means recognizing anxiety and taking care to provide positive classroom experiences. For example, the teacher needs to make sure that the pace and length of a listening activity is not too taxing as the concentration required in trying to comprehend unfamiliar sounds can be tiring. 


\subsubsection{Difficulties Deriving from the Presentation of Speech}

Unplanned and unrehearsed spoken language is very different from the language of written texts. We have to remember that in the real world English is spoken by first language speakers with a variety of accents, and by second language speakers who present an even wider range of phonological features in terms of pronunciation, stress, rhythm, and intonation patterns.

Second language learners need to adjust to all of the variables, especially if they have previously heard only scripted recordings which approximate more to the planned speech of lectures, scripted broadcasting, or drama, delivered at a slow speed and in Standard English. If we are training students ultimately to be able to manage real listening situations, then one implication is that we will need to build their confidence in dealing with authentic speech. Decisions will be needed about the point which learners are exposed to this, the complexity of what they are exposed to, and what kind of tasks will develop confidence.

\subsubsection{Difficulties Because of Gaps in the Message}

Nor only environmental noise but also poorly articulated speech or poor attention can be responsible for creating gaps in the message that a listener hears. When gaps occur, listeners have to reconstruct the missing information and will use whatever clues are available to fill them in. Prediction is a strategy that will help with this. What would also help is the redundancy in the language. It is important to consider the implications of environmental noise for classroom practice. For example, if learners will have to deal with listening to English in noisy environments such as open-plan offices, they may need practice in 'filling in the gaps' with listening texts that have background noise and distorted or obliterated words.

\subsubsection{Difficulties of Applying Various Strategies}

In face-to-face communication, if a gap occurs in the message because of noise or indistinct speech, a listener can ask for clarif ${ }_{1}$ cation.It is quite normal to hear people say 'Sorry, I didn't catch that' or 'could you repeat that, please?' They are the normal strategies we use in $\mathrm{f}_{1}$ rst language communication and they are universal across languages. Listeners use other strategies, too, in order to maintain the flow of conversation. We have ways of indicating that the speaker is holding our interest such as nodding, frowning, using expressions of surprise or concern, making noises such as ' $\mathrm{m} \mathrm{m} \mathrm{m}$ ', 'wow', and 'tut tut', or using words like 'yes', 'I see', and 'right'. We can contribute to the speaker's line of thought by coming in with queries such as 'Are you saying...?' and reformulating what the speaker has just said. Of course, all of these strategies can be used negatively if we wish to indicate disagreement or displeasure. All languages have strategies similar to these, but their precise use may differ and certainly learners will need to know the appropriate words, phrases, and noises to use in each.

\subsubsection{Difficulties of Language}

There are some listening situations in which the language heard is similar to written prose, such as in a lecture which is read, or scripted news broadcast. However, a good deal of listening is to informal colloquial English. Teachers are preparing students for this kind of listening outside the classroom, they need to be aware of its characteristics. Traditionally, the language of audio recordings for ELT has been fairly slow, restricted in various ways, and often repetitive, in order to facilitate comprehension.

There are strong arguments for using recordings with some of the features listed on the right with learners at lower levels. Particularly when the purpose of the listening is for input and the text presents grammar, vocabulary, and certain phonological features. However, if another purpose is to develop the ability to deal with listening outside the classroom, then texts will be needed which present natural language. And this implies familiarizing students with colloquial speech and variety of pace and accent, developing their vocabulary, developing their awareness of how referring expressions such as pronouns are used, and helping them to use any markers in the discourse which will aid prediction.

Chaudron and Richards (1986, p. 115), for example, found that the use of 'macro-markers' in lectures, such as:

What I' $m$ going to talk about today is... One of the problems was... Another interesting development was... You can imagine what happened next...

Assisted students in organizing the major ideas in the lecture. Their study involved giving four versions of the same lecture to different groups of students. A baseline version did not use any particular discourse signals other than those which were strictly necessary to get the information across. A second version was then designed using 'micro-markers', including segmentation markers such as 'now ' and 'right', causal 
markers such as 'so' and 'because', temporal markers such as 'after this' and 'eventually', contrast markers such as 'but' and 'both', and markers of emphasis such as 'actually' and 'of course'. A third version was designed to contain the macro-markers listed above, and a fourth version included both micro-and macro-markers.

The researchers found a consistent result: the version with macro-markers was more conducive to students remembering the content of the lecture. The markers were clues to the overall structure of the lecture and indicated major sections. The micro-markers were less helpful and the researchers hypothesized that perhaps these added little to the substantive content of the lecture but, at the same time, increased the processing load of the listeners. Certainly there is an implication here for the teacher of listening; that helping learners to become aware of and exploit those macro-markers which are available in monologues such as talks, speeches, and lectures is a useful goal.

\subsubsection{Difficulties of Content}

Learners who are unfamiliar with the background knowledge required to make sense of a text will experience difficulty in inferring and interpreting meaning.

In order to understand the content, we need to know something of the conventions surrounding the topic. The language is not likely to cause problems but a lack of schematic knowledge may well do so. The major implication here for teaching listening is the need for a pre-listening stage in which existing prior knowledge can be activated and missing prior knowledge can be introduced.

\subsubsection{Visual Difficulties}

In most situations, listening is not just an aural activity. We are usually able to see the speaker, who provides non-verbal clues to meaning, for example, lip movements, facial expressions, and gestures. In a review of studies exploring the role of vision in speech perception, Kellerman (1990, p. 274) reports evidence that the visual element should not be neglected as speech perception is a bi-modal process. The role of vision in $f_{1}$ rst language listening, especially lip movements, is particularly important when the auditory input is of poor quality. If the speaker is visible in most real listening situations, then the use of audio cassettes in the classroom is unnecessarily restricting. Learners must focus on what they hear and cannot use paralinguistic clues to meaning. Classrooms may have poor acoustics, and recordings may be of poor quality. Also, the teacher has to take time presenting something of the setting so that the contextual clues to meaning are available. The use of audio recordings can provide practice for those situations where the speaker is not visible such as telephone conversations or radio programs, but the availability of video cassettes has undoubtedly assisted learners and has enabled teachers to point out cultural differences in paralinguistic feature such as the use of facial expression and gesture. Many teachers will have experienced diff $_{1}$ culty in persuading learners to return to work with audio cassettes once they have experienced the visual element of video cassettes. Where teachers are fortunate enough to have both video and audio recordings available, perhaps each technical resource should be exploited for its own range of useful activities and, in addition, the teacher, as a live speaker, should come back into prominence for some aspects of listening word. The importance of dealing with these various difficulties from an early stage in the teaching of listening is highlighted by Eastman, who discusses the tendency of intermediate listeners to use translation as they listen, a strategy which is generally considered to be problematic and ineff $\mathrm{i}_{\mathrm{i}}$ cient. Eastman (1991, p. 181)suggests that the reasons for this tendency include anxiety, the expectation that the listener needs to understand every word, transfer from a word-by-word reading comprehension strategy, inadequate prior learning of vocabulary, and inappropriate teaching which fails to contextualize the content of the listening passage or which encourages word-by-word analysis. The issue to which we now turn is how to develop an effective methodology for the teaching of listening, one which deals with the points and pitfalls raised so far.

From the above description, we can find a close relationship between discourse analysis and students' difficulties in listening improvement, so the application of the study of discourse analysis to assist students' listening comprehension is feasible. Discourse analysis suggests a way of studying formal features of language across sentence to arrive at high level discourse interpretation, makes up for the disadvantages of traditional approach and hence opens up a wider perspective for teaching of listening.

\subsection{The Experimental Results and Discussion}

\subsubsection{The Comparison between the Two Tests of the Control Group}

Table 1 is the result of Paired Samples Test. The value of df is 29. P, that is, Sig. (2-tailed) is 0.119. Because the 
value of $\mathrm{P}>0.05$, the listening proficiency of the pretest and the posttest are not significantly different. Based on the statistics of Table 1 and Table 1, we can say that the traditional approach of EFL listening teaching does not efficiently help students make improvement in listening proficiency.

Table 1. Paired samples test

\begin{tabular}{|c|c|c|c|c|c|c|c|}
\hline & \multicolumn{4}{|c|}{ Paired Differences } & \multirow{3}{*}{$\mathrm{t}$} & \multirow{3}{*}{$\mathrm{df}$} & \multirow{3}{*}{$\begin{array}{l}\text { Sig. } \\
\text { (2-tailed) }\end{array}$} \\
\hline & \multirow{2}{*}{ Mean } & \multirow{2}{*}{$\begin{array}{l}\text { Std. } \\
\text { Deviation }\end{array}$} & \multirow{2}{*}{$\begin{array}{l}\text { Std. Error } \\
\text { Mean }\end{array}$} & $\begin{array}{l}95 \% \text { Confidence Interval } \\
\text { of the Difference }\end{array}$ & & & \\
\hline & & & & Lower & & & \\
\hline Pair 1 PRE-POST & -.9333 & 3.1833 & .5812 & -2.1220 & -1.606 & 29 & .119 \\
\hline
\end{tabular}

a. $\mathrm{GROUP}=1$.

\subsubsection{The Comparison between the Two Tests of the Experimental Group}

Table 2. Paired samples statistics

\begin{tabular}{llllll}
\hline & & Mean & N & Std. Deviation & Std. Error Mean \\
\cline { 3 - 6 } Pair 1 & PRE & 5.9667 & 30 & 1.4016 & .2559 \\
& POST & 8.4000 & 30 & 2.3134 & .4224 \\
\hline
\end{tabular}

a. $\mathrm{GROUP}=2$.

When the comparison of the pretest and posttest of the same group is conducted, Paired Sample T-test should be employed. Table 2 is Paired Samples Statistics. From Table 2, we can see that the mean score of pretest is 5.9667, posttest is 8.4000 . The mean score of posttest is greatly higher than that of pretest. The Standard Deviation of pretest is 1.4016 , posttest is 2.3134 . That is to say, the score of pretest is small diversed than posttest.

Table 3. Paired samples test

\begin{tabular}{|c|c|c|c|c|c|c|c|c|}
\hline & \multicolumn{5}{|c|}{ Paired Differences } & \multirow{3}{*}{$\mathrm{t}$} & \multirow{3}{*}{ df } & \multirow{3}{*}{$\begin{array}{l}\text { Sig. } \\
\text { (2-tailed) }\end{array}$} \\
\hline & \multirow{2}{*}{ Mean } & \multirow{2}{*}{$\begin{array}{l}\text { Std. } \\
\text { Deviation }\end{array}$} & \multirow{2}{*}{$\begin{array}{l}\text { Std. Error } \\
\text { Mean }\end{array}$} & \multicolumn{2}{|c|}{$\begin{array}{l}95 \% \text { Confidence Interval } \\
\text { of the Difference }\end{array}$} & & & \\
\hline & & & & Lower & Upper & & & \\
\hline Pair 1 PRE-POST & -2.4333 & 2.6351 & .4811 & -3.4173 & -1.4494 & -5.058 & 29 & .021 \\
\hline
\end{tabular}

a. GROUP $=2$.

Then we come to Table 3. It is the result of Paired Samples Test. The value of $\mathrm{df}$ is 29. P, that is, Sig. (2-tailed) is 0.021 . Because the value of $\mathrm{P}<0.05$, the listening proficiency of the pretest and the posttest are significantly different. Based on the statistics of Table 2 and Table 3, we can say that the discourse-oriented approach of EFL listening teaching to some extent efficiently help students make further improvement in listening proficiency.

\section{Conclusion}

\subsection{Implications}

Discourse refers to a meaningful series of utterances used in a specific context or stretches of language perceived to be meaningful, unified and purposive. The relation between the language and the context in which it is used is studied in the discourse analysis. Cohesion and coherence are two important terms in discourse analysis and considerable attention has been focused on cohesion and coherence. Although different linguists have different views on relations between cohesion and coherence, they all concur that both of them play a very important role in textual composition and textual comprehension. They are not only cores of discourse analysis but also ways of thinking. However, the cohesion and coherence knowledge itself cannot guarantee the improvement of listening 
comprehension. Therefore, another two theories in discourse analysis are put forward, that is, schema theory and relevance theory.

Schema theory is currently widely used in the teaching of reading, writing as well as listening comprehension. It accounts for the role of the listener's background knowledge in language comprehension and tells us that the language comprehension is a process between new information and the old one. Although schema theory contributes greatly to discourse interpretation, it is still imperfect, because it cannot provide explicit explanation of all the phenomena or processes concerning listening comprehension. Therefore, relevance theory is used as a compensation for the disadvantages of schema theory on language interpretation. As a whole, relevance theory aims at explaining discourse relevance from the perspective of cognitive science, and hence disclosing psychological devices of discourse interpretation. Although the main purpose of relevance theory is by no means to explain discourse coherence, this theory has provided coherence theory with beneficial supplement.

There are also some other concepts in discourse analysis, which are very important for successful listening comprehension. Discourse markers are important to the study of language acquisition because the particular pragmatic, semantic and syntactic features that define them demonstrate the subtle interplay between form and function. However, texts are sometimes coherent not because of the discourse markers but because the information in them is structured in a particular way. Many texts are organized into larger patterns, as listeners, we can use to help find out our way round the information in a text. They are mainly: Question-answer pattern, claim-counterclaim pattern, general-specific pattern, rhetorical pattern and background-problem-solutionevaluation pattern. Another important concept mentioned is context, which can be divided into two categories: the linguistic context and the non-linguistic context. It plays an important role in discourse interpretation. According to me, to achieve better understanding of context constructing coherence, listeners are surely to bridge over the difficulties with some covert cohesive devices as follows: context, discourse structure, background knowledge, language style and discourse topic.

From the above experimental results, we can see discourse-oriented approach is more efficient than the traditional listening teaching approach in helping students make further improvement. In conducting a discourse-oriented approach in college English class, three elements are worth considering. First, in order to build new background knowledge and activate existing background knowledge of listening content, teachers can include the following pre-listening activities: viewing movies, listening to related songs or speeches, class discussions or debates role-play activities, predictions about the text; introduction and discussion of new words in the text. Second, in recent EFL listening classroom, the class time is mainly spent on assessment and practice rather than direct students on comprehension skills in the actual teaching of comprehension. In a discourse-oriented listening class, more emphasis should be put on how to listen and how to comprehend the texts. Students should be encouraged to activate their background knowledge, their existing schemata through self-generated questions about the text they are to listen to. Third, according to the difficulties students have in listening, we can conclude selection of appropriate listening material is of great importance. Interest of the material is the first consideration to build students' confidence in listening activity. Students can even select listening materials autonomously. Then, specialized content area is believed to help students build schemata and facilitate comprehension. To have students listen in depth in a content area allows students to become more familiar with a single area, an author's style, or the specialized vocabulary of a topic and develop enough context to facilitate comprehension. With one content area satisfactorily finished, the listening can move on to the next one.

There are also some other concepts in discourse analysis, which are very important for successful listening comprehension. Discourse markers are important to the study of language acquisition because the particular pragmatic, semantic and syntactic features that define them demonstrate the subtle interplay between form and function. However, texts are sometimes coherent not because of the discourse markers but because the information in them is structured in a particular way. Many texts are organized into larger patterns, as listeners, we can use to help find out our way round the information in a text. They are mainly: Question-answer pattern, claim-counterclaim pattern, general-specific pattern, rhetorical pattern and background-problem-solutionevaluation pattern. Another important concept mentioned is context, which can be divided into two categories: the linguistic context and the non-linguistic context. It plays an important role in discourse interpretation. According to me, to achieve better understanding of context constructing coherence, listeners are surely to bridge over the difficulties with some covert cohesive devices as follows: context, discourse structure, background knowledge, language style and discourse topic.

It's no doubt that the application of discourse analysis in listening comprehension can work wonders. However, it's no easy job to apply the theory to the practice. I adopted a discourse-oriented approach which divided the 
listening process into three stages: pre-listening stage, while-listening stage and post-listening stage. At each stage, the teachers are required to apply the discourse analysis in listening comprehension. At the same time, an experiment is performed, the result of which demonstrates that the discourse approach is more effective in improving the student's listening comprehension ability.

\subsection{Recommendations for Future Research}

Finally, the present study has to be complemented by further research achievements on discourse and listening comprehension. Since the discourse analysis, as a new branch of linguistics, is still incomplete and under development and people's understanding of listening comprehension will be furthered.

\section{Acknowledgements}

The research gets funds from Sichuan Center for Education Development Research (No. CJF14005).

\section{References}

Brown, G., \& Yule, G. (1983). Discourse Analysis. Cambridge: Cambridge University Press.

Chaudron, C., \& Richards, J. C. (1986). The effect of discourse markers on the comprehension of lectures. Applied Linguistics, 7(1), 113-127. http://dx.doi.org/10.1093/applin/7.2.113

Cook, G. (1989). Discourse. Oxford: Oxford University Press.

Eastman, J. K. (1991). Learning to listen and comprehend: The beginning stages. System, 19(3), 179-188.

Faerch, C., \& Kasper, G. (1986). The role of comprehension in second language learning. Applied Linguistics, 7(3), 257-274. http://dx.doi.org/10.1093/applin/7.3.257

Halliday, M. A. K., \& Hasan, R. (1976). Cohesion in English. London: Longman.

Harris, Z. (1952). Discourse Analysis: A Sample Text. Language, 28, 1-30. http://dx.doi.org/10.2307/409987

Kellerman, S. (1990). Lip-service: The contribution of the visual modality to speech perception and its relevance to the teaching and testing foreign language listening comprehension. Applied Linguistics, 11(3), 272-280. http://dx.doi.org/10.1093/applin/11.3.272

McCarthy, M. (1991). Discourse Analysis for Language Teachers. Cambridge: Cambridge University Press.

Schiffrin, D. (1972). Discourse Markers. Cambridge: Cambridge University Press, 1987.

\section{Copyrights}

Copyright for this article is retained by the author(s), with first publication rights granted to the journal.

This is an open-access article distributed under the terms and conditions of the Creative Commons Attribution license (http://creativecommons.org/licenses/by/3.0/). 